\title{
A DETAILED RECORD OF THE LOWER JARAMILLO POLARITY TRANSITION FROM A SOUTHERN HEMISPHERE, DEEP-SEA SEDIKEKT CORE
}

\author{
Bradford M. Clement and Dennis V. Rent
}

Lamont-Doherty Geological Observatory and Department of Geological Science, Columbia Oniversity

\begin{abstract}
A detailed record of the lover Jaramillo (reveraed to normal) polarity tranaition was obtained from a southern hemisphere, deep-sea sediment core (latitude $=35.91^{\circ} \mathrm{E}$, longitude $=59.97^{\circ} \mathrm{Z}$ ) The record consists of over 850 amples taken across $140 \mathrm{~cm}$ of section. The transition itself is recorded across approximate1y $70 \mathrm{~cm}$ and is represented by more than 475 specimens from about 160 levels giving intermediate directions. The transition is identified by a nearly $180^{\circ}$ shift from directions in good agreement with a reversed, axial dipole field to those closely aligned with a normal, axial dipole field for the core ite latitude. The inclinations shallow gradually early in the reversal and pass through very steep negative values $\left(-80^{\circ}\right)$ late in the transition. The declinations show little appreciable variation until the inclinations have moved through the near vertical, and then slowly approach values in agreement with a normal polarity field. An intensity low accompanies the directional change during wich the intensity drops to less than $15 \%$ of the maximum values observed in this sample interval. The intensity fluctuation spans a vider interval than the directional change, decreasing prior to any systematic change in the directions and then increasing to pre-transition levels by the same depth at which the directions have stabilized. The VGP path conetructed for this reversal is longitudinaly constrained to a certain extent, between $140^{\circ}$ and $230^{\circ}$ for intermediate VGP latitudes and is roughly centered $120^{\circ}$ from the aite longitude. This path is therefore a far-sided VGP path in Hoffman's [1977] terminology. Assuming a constant sedimentation rate $(67 \mathrm{~m} / \mathrm{Ma})$ through the Jaramillo Subchron, the duration of the transition is estimated to be 11,200 years to 4,500 yearg (depending on the criteria) for the directional change, whereas the associated intensity variation occurred over 15,000 to 20,000 years. Considered together with records of the most recent reversal (Matuyama/Brunhes) in light of current transitional field models, this record otrongly suggests that the lower Jaramillo transitional field was dominated by different harmonics than the Matuyama/Brunhes transitional field.
\end{abstract}

\section{Introduction}

Although the fact that the earth's magnetic field undergoes frequent polarity reversals has been vell established for over two decades, the reversal process itself is still very poorly defined. Paleomagnetic records of polarity tran-

Copyright 1984 by the American Geophysical Dnion.

Paper number $3 B 1726$.

$0148-0227 / 84 / 003 B-1726 \$ 05.00$ sitions can provide information about the behavior of the geomagnetic field during a rever$8 a 1$ and therefore may be capable of placing constraints on possible reversal mechanisms. In recent years, several polarity transition records have become available, allowing the development of transitional field mode1s (Hoffman, 1977; Hoffman and Fuller, 1978; Fuller et al., 1979; Hilliams and Fuller, 1981; Hoffman, 1982). These models generally assume that the transitional field was dominated by axisymmetric fields, predicting a dependence mainly upon the site latitude for tranaitional records. The available records, however, are not from widely distributed sites, and in fact a lmost all are from northern hemisphere mid-latitudes. This poor distribution, and in particular the lack of southern hemisphere records, has left these models poorly conatrained. In addition, there is a poor temporal distribution of these records, with the Matuyama/ Brunhes reversal being the only one for which multiple, detailed records exist. The few detailed records of earlier reversals, of both reversed to normal (R-N) and normal to reversed $(N-R)$ sense, do not yet allow definite statements to be made regarding possible differences from one reversal to another.

We resampled the lower Jaramillo transition as it is recorded in deep-sea core RC14-14 in an effort to obtain a detailed southern hemisphere record of a reverse to normal polarity transition. This transition was firat reported by Opdyke et 1 . [1973]. The very high apparent sedimentation rate across critical intervals and the exceptional quality of the magnetic data in this core provided the incentive to otudy this transition in more detail.

\section{Core Description}

Deep-sea core RC14-14 was taken in the Crozet Basin at $35.91^{\circ}$ south latitude, $59.97^{\circ}$ east longitude. It consists of radiolarian and diatom lutite that, in the interval of interest here, occurs in very fine laminae, suggesting minimal disturbance from bioturbation. The magnetostratigraphy of this core as interpreted by opdyke et a1. [1973], based on the stable natural remanent magnetization (NRM) of the sediment, is defined by four distinct polarity zones. A zone of reversed polarity extends from the top of the core to a depth of $460 \mathrm{~cm}$ followed by a normal polarity zone from $460 \mathrm{~cm}$ to $940 \mathrm{~cm}$. From $940 \mathrm{~cm}$ to $2250 \mathrm{~cm}$ the sediment is reversely magnetized with the rest of the core below $2250 \mathrm{~cm}$ being normally magnetized. As the top of the core is reversely magnetized it is apparent that the Brunhes polarity zone is misaing and therefore the interpretation of the magnetostratigraphy was not atraightforward. It was, hovever, possible to identify the polarity transition at $2250 \mathrm{~cm}$ as 


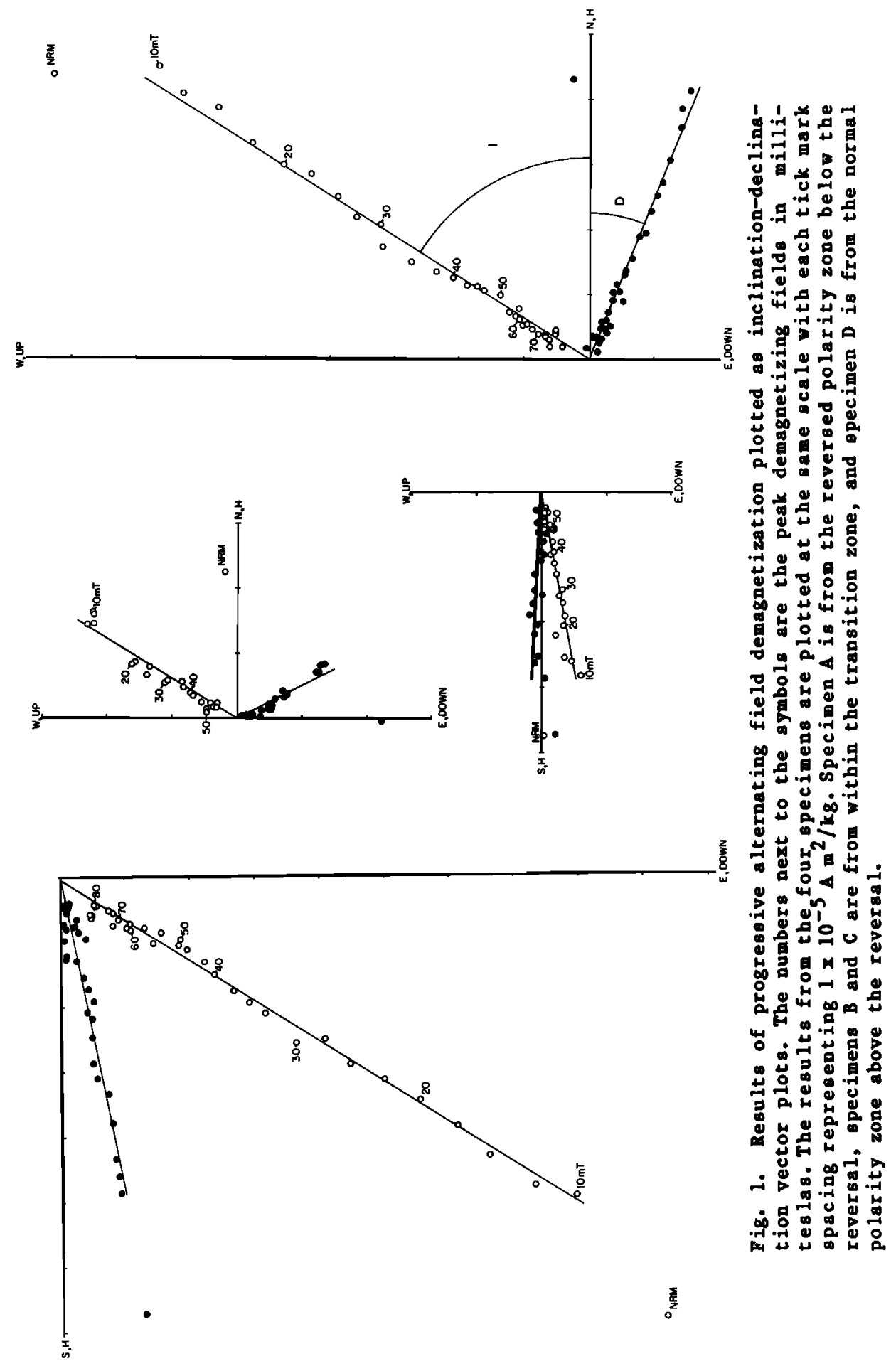


the upper 0lduvai based on the extinction of Clathrocrlas bicorpus. The normal polarity zone from $2250 \mathrm{~cm}$ to $258 \mathrm{~cm}$ (the bottom of the core) was therefore correlated to the Olduvai Subchron and the normal polarity zone from $460 \mathrm{~cm}$ to 940 cm to the Jaramillo Subchron.

The thickness of the Jaramillo Subchronozone ouggesta a high sedimentation rate in this core although the absence of the Brunheg magnetozone and the disproportionately short Matuyama magnetorone suggest that periods of faot sedimentation must have alternated with periods of nondeposition or erosion. The observation of intermediate directions within the trangitions by opdyke et al. [1973], even using standard gampling techniques (2.5-cm samples), ouggests high resolution recording of the transitions. In light of these results ve resampled the remaining split half of this core by using a much more detailed ampling technique in an attempt to improve the resolution. Data for the lower Jaramillo transition are reported here; similar work on the two N-R reveraals (top of the olduvai and top of the Jaramillo) is in progress.

\section{Experimental Procedures}

The lower Jaramillo reversal was placed at approximately $940 \mathrm{~cm}$ by Opdyke et al. [1973], leading us to ample the core continuousiy from a depth of $1010 \mathrm{~cm}$ to $870 \mathrm{~cm}$. Successive slices of sediment, $0.3 \mathrm{~cm}$ to $0.5 \mathrm{~cm}$ thick, were cut from the dried core using a jeweler's saw. Each slice was subdivided to yield three specimens per sampling level. These specimens were weighed and then glued in a known orientation in plastic boxes for measurement. The average specimen measures $8 \mathrm{~mm} \times 8 \mathrm{~mm} \times 4 \mathrm{~mm}$ and weighs $0.4 \mathrm{~g}$.

The direction and magnitude of the NRM of each specimen were measured by using a two-axis cryogenic magnetometer with a $6.8 \mathrm{~cm}$ access. Progressive alternating field (A.F.) demagnetization studies were carried out at $2.5 \mathrm{mr}$ increments on 20 pilot specimens distributed over the section (1 to 2 specimens from every $10 \mathrm{~cm}$ ). On the basis of the results of these studies a blanket treatment of $10 \mathrm{mT}$ was applied to the rest of the opecimens by using a ingle axis commercial ac demagnetizer.

Opdyke et al.'s [1973] studies of the anhysteretic remanence (ARM), saturation isothermal remanence and initial suceptibility indicated that there are no dramatic changes of magnetic mineralogy with depth across the polarity trangitions. Additional ARM analyais was undertaken here to examine the possibility of changes on the scale of this study. Samples were taken every 5 cm through the sampled section and, on the basis of evidence of approach to saturation values in ARM acquisition experiments, were given an ARM using a $0.05 \mathrm{mT}$ de field coaxial with a $180 \mathrm{mT}$ a ternating field.

\section{Result:}

The results of progressive A.F. demagnetization of four pilot specimens are shown in Figure 1, plotted as inclination/ declination vector diagrams [zijderve1d, 1967]. These are plotted by using the same scale in order to emphaize the change in directions and WRM intensities observed across the transition. Figure la illustrates the behavior of a secimen taken from the reversed polarity zone, about $20 \mathrm{~cm}$ below the reversal. Figure $1 b$ and $1 c$ show results from specimens taken from within the transition zone, while Figure 1d illuetrates data from a specimen from the normal polarity zone above (about $15 \mathrm{~cm}$ ) the reversal.

It is clear from these plots that despite the small size of the specimens a stable magnetization can be readily measured by using a cryogenic magnetometer. Treatment at $10 \mathrm{mT}$ removes a small viscous magnetization, isolating a component that decays linearly to the origin with further A.F. treatment up to $80 \mathrm{mT}$ to $90 \mathrm{mT}$. Such behavior of samples taken from within the transition interval demonstrates that the observed intermediate directions are not the result of complex multicomponent magnetizations. Instead, the univectorial magnetization component isolated after 10 $\mathrm{mT}$ is thought likely to represent a record of the direction of the geomagnetic field near the time of deposition.

The transition record obtained after partial demagnetization at $10 \mathrm{mT}$ is shown in Figure 2; the results from the three specimens at each sampling level are plotted to allow judgement of the internal consiatency of the data. The transition is identified by a gradual, nearly $180^{\circ}$ directional change from reverse to normal polarity across approximately $70 \mathrm{~cm}$ of section. A decrease in remanent intensity accompanies the directional change with NRM intensities decreasing to less than $15 \%$ of the maximum values observed outside the transition.

The directional data show very tight within and between level grouping both in the reversed polarity interval sampled below (mean $D=180.0^{\circ}$, $\mathrm{I}=54.1^{\circ}$, a $1 \mathrm{pha} 95=5.15^{\circ}, \mathrm{k}=41.2$ for $\mathrm{n}=20^{\circ}$ levels from $979.4 \mathrm{~cm}$ to $989.3 \mathrm{~cm}$ ) and the norma 1 polarity interval above the reversal (mean $D=$ $22.9^{\circ}, I=55.2^{\circ}$, a 1 pha $95=5.6^{\circ}, k=67.2$ for $n$ = 19 levels from $880.0 \mathrm{~cm}$ to 890.8 ). These mean inclinations for norma 1 and reverged polarity intervals are almost identical irreapective of ign and agree closely vith the axisl dipole field value of $55^{\circ}$ expected for the core site latitude. We regard these agreements as providing strong evidence that these sediments have accurately recorded the geomagnetic field.

The mean declinations for the normal and reversed intervals, however, fall short of being antipoda 1 by $23^{\circ}$. This core was not oriented with respect to arimuth when taken, so the observed declinations were measured relative to the split face of the core. Even relative declination values are therefore dependent upon how well the internal orientation of the core was maintained since its retrieval. Although the declination change with respect to the internal orientation closely approaches that expected for a full polarity reversa1, there is the possibility of a core twist or of a core break, perhaps coinciding with the apparent discontinuity in the record observed at $924 \mathrm{~cm}$. This break will be discussed in detail later.

The transition from reverse to normal polarity (Figure 2) occurs across approximately $70 \mathrm{~cm}$ of section. The inclination record is characterized by a gradual shallowing trend early in the reversal after which the directions pass through 


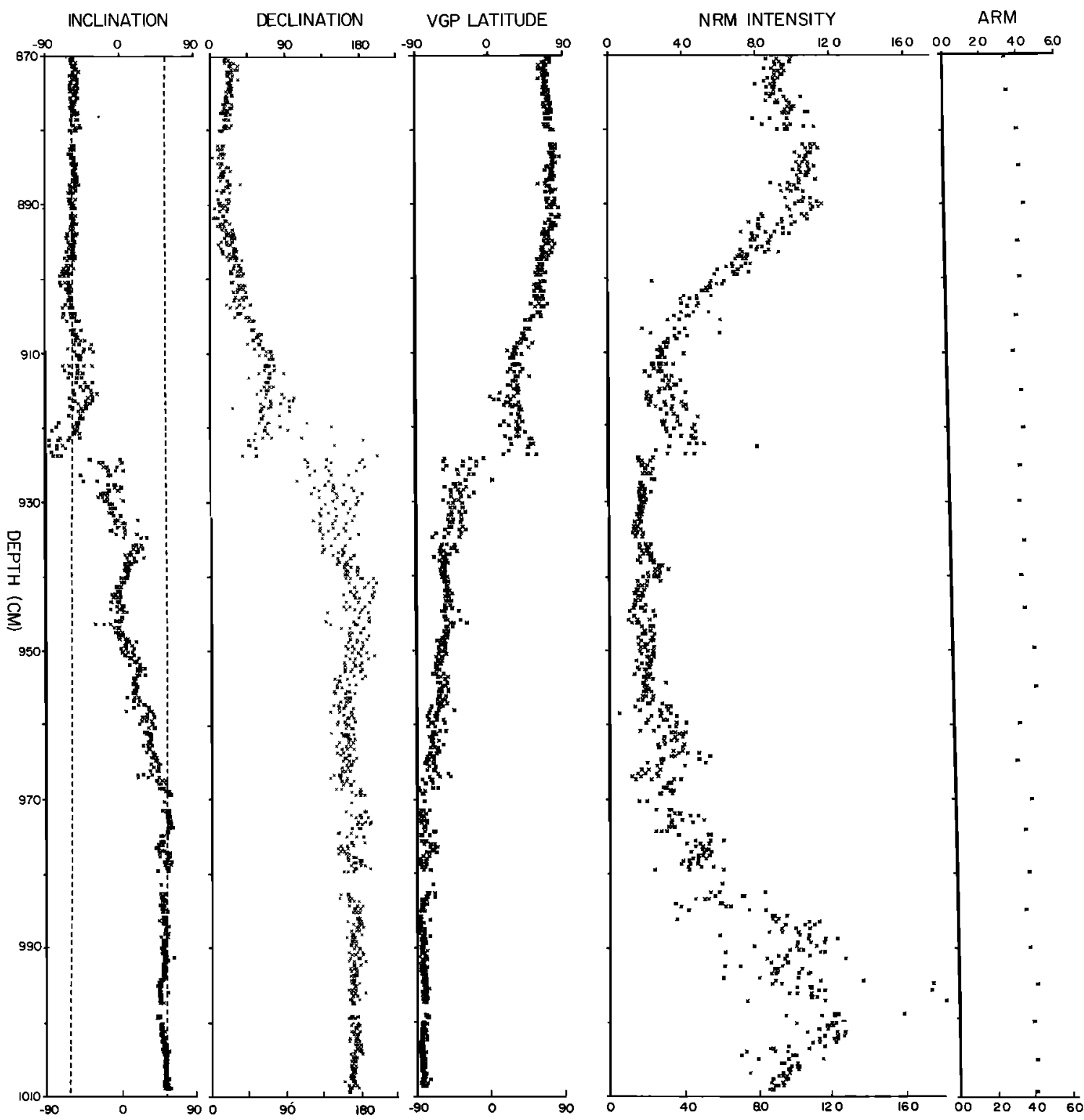

Fig. 2. Paleomagnetic results from RC14-14 after A.F. demagnetization at $10 \mathrm{mT}$ plotted with depth from the core top in centimeters. Inclination (A), declination (B), and VGP latitude (C) are plotted in degrees; $A R Y$ intensity (D) plotted in $10^{-4} \mathrm{~A} \mathrm{~m}^{2} / \mathrm{kg}$; and NRM intensity normalized to specimen weight (E) plotted in units of $10^{-5} \mathrm{~A} \mathrm{~m} / \mathrm{kg}$.

very high, negative values before returning to normal polarity dipole inclinations. On the other hand, the declinationa show very 1 itt le change early in the reversal and only begin to change as the inclinations approach near vertical values. The NRM intensity record is characterized by a broad, roughly symmterical trough, which is not vell centered about the directional change.

In detail, the inclinations begin to ohallow gradually at $970 \mathrm{~cm}$, moving away from values very near to those predicted by a reversed axial dipole field $\left(55.4^{\circ}\right)$ and become nearly horizontal by $948 \mathrm{~cm}$. The directions remain approximate1y flat from $948 \mathrm{~cm}$ to $924 \mathrm{~cm}$ with departures of up to $25^{\circ}$ at $935 \mathrm{~cm}$ and $930 \mathrm{~cm}$. An apparent discontinuity exists in the record at $924 \mathrm{~cm}$ across which the inclinations abruptly become very steep in an upward direction $\left(-80^{\circ}\right)$ from $924 \mathrm{~cm}$ to 920 cm. The inclinations then ahallow to less than dipole values before grouping at $-55^{\circ}$ by $905 \mathrm{~cm}$.

The declinations remain nearly constant from $1010 \mathrm{~cm}$ to $940 \mathrm{~cm}$ but begin to rotate toward normal polarity directions above $940 \mathrm{~cm}$. From 935 $\mathrm{cm}$ to $924 \mathrm{~cm}$ an increasing dispersion appears in the declination data, which is manifest to a lesser extent in the inclination data as well. A portion of the declination dispersion is a result of the very steep inclinations and does not necessarily indicate a poor grouping of the total vector. This, however, cannot account for the total dispersion observed as will be discussed later. From $924 \mathrm{~cm}$ to $893 \mathrm{~cm}$ the declinations change by more than $35^{\circ}$ with no further ignificant trend apparent in the data above 893 cm.

The intensity lov (Figure 2e) associated with 
the directional change occurs across more than a meter of section. Immediately preceeding and following the low are what appear to be intensity highs. The record, however, is not sufficiently long to determine if these highs are within the range of non-transitional fluctuations. The intenoity high preceeding the reversal is observed from $1005 \mathrm{~cm}$ to $990 \mathrm{~cm}$ as the intensity increases upcore from $9.0 \times 10^{-5} \mathrm{Am}^{2} / \mathrm{kg}$ to a mean of $11.0 \times 10^{-5} \mathrm{Am}^{2} / \mathrm{kg}$ before beginning to decrease (at $990 \mathrm{~cm}$ ). The intensity values decrease by $80 \%$ across $20 \mathrm{~cm}$ (from $990 \mathrm{~cm}$ to $970 \mathrm{~cm}$ ) before any change in the remanent directions occur and have decreased by 857 at $958 \mathrm{~cm}$ where they remain relatively constant from $958 \mathrm{~cm}$ to $924 \mathrm{~cm}$ at 1.5 $x 10^{-5} \mathrm{Am}^{2} / \mathrm{kg}$. A small, abrupt increase at $924 \mathrm{~cm}$ marks an apparent discontinuity in the record, above which the intensity drops slightly before beginning to increase in a linear manner. This increase occurs from $910 \mathrm{~cm}$ to $892 \mathrm{~cm}$ as the values return to a mean of $11.0 \times 10^{-5} \mathrm{Am} / \mathrm{kg}$ before decreasing again to nearly $9 \times 10^{-5} \mathrm{Am}^{2} / \mathrm{kg}$ by $875 \mathrm{~cm}$. The intensity increase begins while the remanent directions can still be considered to be transitional and the maximum intensity is reached at approximately the same depth at which the directions stabilize at the normal polarity dipole direction.

Variations in the intensity of magnetization may be reflecting changes in field behavior or changes in the amount or type of magnetic minerals present. Opdyke et a1. [1973] used a number of methods, including saturation isothermal remanent magnetization, bulk susceptibility, and ARM measurements, which are used to normalize the intensity record for lithologic variations. Additional work indicates that the ARM method may be the most effective of these as it often appears to be represented by the same magnetic fraction that carries the natural remanent magnetization [Levi and Bannerjee, 1976]. The ARM intensitie are plotted in Figure $2 \mathrm{~d}$ and revea 1 very little variation, suggesting that there are no marked changes in magnetic mineralogy across the transition (mean $-3.93 \times 10^{-4} \mathrm{Am} / \mathrm{kg}$, standard deviation $=0.39 \times 10^{-4} \mathrm{Am}^{2} / \mathrm{kg}$ for $\mathrm{n}=29$ ). This implies that the observed NRM intensity record is not strongly controlled by changes in the nature or amount of the magnetic carrier but may instead reflect changes in the geomagnetic field intensity across the polarity transition.

\section{Virtual Geomagnetic Poles}

Although this core only has internal azimuthal orientation it is possible to calculate virtual geomagnetic poles ( $\nabla \mathrm{PPB}_{\mathrm{B}}$ ) for these results by making a deliberate adjustment to the data. The entire declination record across the transition was uniformly reoriented so that the mean reversed declination was set to $180^{\circ}$. Justification for this adjustment is based on the excellent agreement of the mean normal and reversed inclinations with the predicted axial dipole values from which we can infer that the mean declinations for the same intervals should lie along a meridian. The latitude of the VGP calculated for each specimen is shown in Figure $2 c$. The VGP latitudes move gradually from near $-90^{\circ}$ below $970 \mathrm{~cm}$ to nearly $+90^{\circ}$ above $893 \mathrm{~cm}$. Again as in the other records (inclination, declina- tion, and intensity) this gradual ohift is interrupted by an apparent break at $924 \mathrm{~cm}$.

The VGP patb calculated for this reversal is shown in Figure 3. Each VGP was calculated from the unit vector mean [Fisher, 1953] of the three observed directions at each sampling level. The resulting path is somewhat longitudinally constrained, 1 ying between $140^{\circ} \mathrm{E}$ and $230^{\circ} \mathrm{E}$ long $\mathrm{i}-$ tude, and is roughly centered over the $180^{\circ} \mathrm{E}$ meridian. As the path falls more than $90^{\circ}$ from the site longitude it is clasified a a farsided VGP path. It is interesting that the points on this path fall in a series of discrete clusters centered at $60^{\circ} \mathrm{S}, 190^{\circ} \mathrm{E} ; 35^{\circ} \mathrm{S}, 180^{\circ} \mathrm{E}$; $35^{\circ} \mathrm{N}, 155^{\circ} \mathrm{E}$ and $60^{\circ} \mathrm{N}, 170^{\circ} \mathrm{E}$. This may indicate that the geomagnetic field changed in a sporadic manner during this interval or that the recording process was discontinuous on this ocale. The latter is thought to be a likely contributing factor as this section of the core is laminated, a feature that in itself suggests nonuniform sedimentation.

The VGP positiona for the normal polarity interval appear offot from the north pole because as noted earlier, the normal and reversed polarity declinaitons fall short of being antipodal by $23^{\circ}$. If it is assumed that the discontinutig observed at $924 \mathrm{~cm}$ represents a core break, then it is reasonsble to suggest that the declination offset across it may be the result of a differential rotation of the core. An adjusted VGP path was therefore calculated after uniformly rotating the declinations above the discontinuity by $23^{\circ}$ (Figure 3 ). The problems associated with the discontinuity vill be discussed in detail later; however, the modified VGP path illustrates the extent of the possible distortion of the record if the core actually did break at this leve1.

\section{Interpretation of Data}

The method of taking three specimens (A, B, and C) for measurement at each sampling level allowed the recognition of a local zone of inhomogenous magnetization in this core. Beginning at approximtely $940 \mathrm{~cm}$ and continuing upcore to 924 cm, a divergence, which increases upcore to 924 $\mathrm{cm}$ and then decreases to $920 \mathrm{~cm}$, is observed in the declinations of the $A, B$, and $C$ specimens. In addition, from $924 \mathrm{~cm}$ to $920 \mathrm{~cm}$, the A specimen inclinations are up to $20^{\circ}$ steeper than the $B$ and C inclinations. While this within level behavior definitely seems to suggest that this section of the core has been deformed, the combined inclination and declination behavior cannot be readily explained by a simple shearing or twisting that might be attributed to the coring process.

The deformed zone is further complicated by an abrupt discontinuity at $924 \mathrm{~cm}$. Since the nearest physical breaks in the dried core were at $913 \mathrm{~cm}$ and $926 \mathrm{~cm}$ this does not appear to be the result of an improper orientation of the core segments. The discontinuity possibly could have been caused by failure at this level as the core twisted during the coring or extrusion process. Such a break might explain why the observed declinations are not exactly antipoda1. The core photographs show a thin, dark lamination at about $924 \mathrm{~cm}$ which may be an indication of a sedimentological break in the record and therefore offers an 


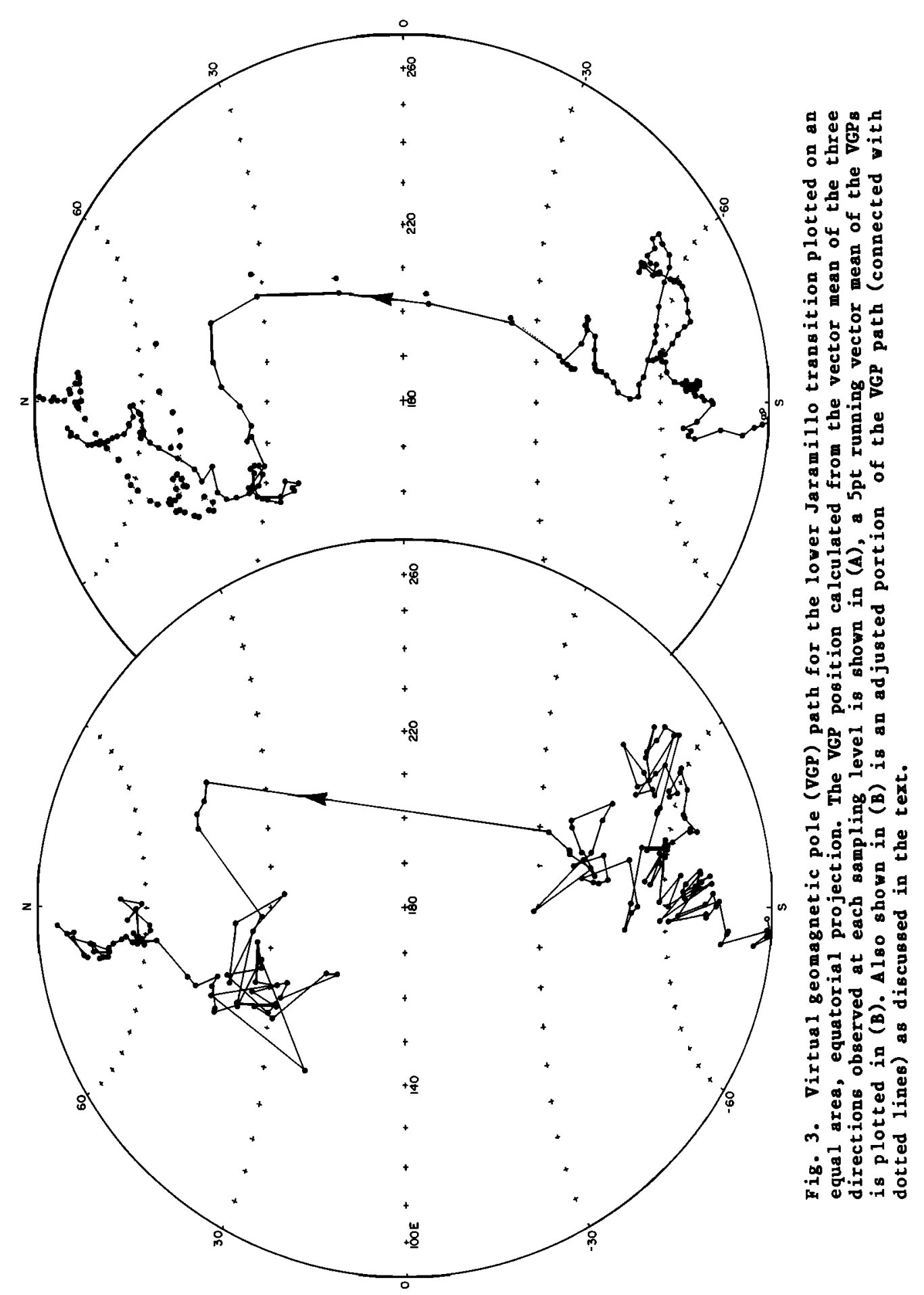


alternative explanation for the discontinutiy in the paleomagnetic record. As the discontinuity is observed in the intensity data as well as the directional record, it may be the result of an interruption in deposition and therefore may be revealing the presence of a hiatus in the section. Even if this is hiatus, some form of inhomogenous deformation must have occurred to produce the observed directional behavior. Perhaps the divergence in decinations was caused by a slight curling of the core about its long axis as it dried. In summary, given the variables involved, it is not possible to determine the exact form of deformation this zone represents. For this reason the directions within this interval ( $940 \mathrm{~cm}$ to $920 \mathrm{~cm}$ ) may be regarded with some suspicion, although it cannot be ruled out that their general character is representative of field behavior.

The reversal record presented here is of such high resolution that it becomes apparent that the lower boundary of the Jaramillo Subchronozone can vary by tens of centimeters depending on the criteria used to define that boundary. By convention in magnetostratigraphy the boundaries of polarity zones are defined by the mid-points of the transition zone separating the two polarity zones. This method originated when dealing that records which contained very little detail of polarity transitions. In cases where details vere available, workers sometimes determined the boundaries on the basio of the directional change, for example, a the point where the inclination passes through zero. When working with records of high resolution the difference between these two methods becomes further complicated by the prediction of current trangitional field models that the directional behavior as well as the duration of the directional change will be a function of the site location [Williams and Fuller, 1981; Fuller et al., 1979; Hoffman and Fuller, 1978; Hoffman, 1977]. If these models are valid, then placing the boundary of a polarity zone at the mid-point of the transition or at the point of some given directional characteristic will not be placing the boundary at exactly isochronous levels in records from geographically distributed sites.

The difficulty in pin-pointing transition boundarieg must be born in mind when defining and comparing polarity boundaries in high-resolution records from different sites. The choice of methods will be governed by the understanding of transitional field behavior and therefore will be dependent upon the existing reversal models. In the light of the williams-Fuller model, it appears that using the mid-point method is likely to produce a more accurate estimate of the polarity zone boundary than one based on directional features simply because their model predicts highly asymmetrical directional records that vary more than the transition duration with site latitude. In determining the lower boundary of the Jaramillo Subchronozone we have therefore used the directional mid-point. The mid-point is placed at $930.5 \mathrm{~cm}$ if the transition zone boundaries are taken as $968 \mathrm{~cm}$ and $893 \mathrm{~cm}$. Opdyke et a1. [1973] placed the upper boundary of the Jaramillo at $460 \mathrm{~cm}$ using the same method. By this criterion, the Jaramillo Subchronozone is 470.5 cm thick. As discussed by Mankinen et al. [1980] the best eotimate for the duration if the Jaramillo Subchron is 70,000 years, which indicates an average sedimentation rate of $67 \mathrm{~m} / \mathrm{Ma}$ for this section of the core.

The duration represented by the thickness of the transition zone can be estimated by assuming constant deposition at the calculated rate. In a high resolution record, the arbitrary decision of where the tranoition boundaries are placed has an important effect on time estimates. If the transition zone boundarieg are placed where the directione tend to exceed the circular standard deviation [Fisher, 1953] of the normal and reversed means $\left(10^{\circ}\right.$, calculated from the mean of the interval $880.0 \mathrm{~cm}$ to $890.0 \mathrm{~cm}$; and $13^{\circ} \mathrm{calcu}-$ lated from the mean of the interval $979.4 \mathrm{~cm}$ to $989.3 \mathrm{~cm}$, respective $1 \mathrm{y})$, then the transition is $75 \mathrm{~cm}(893.3 \mathrm{~cm}$ to $968.0 \mathrm{~cm})$ thick and the resulting duration estimate is 11,200 years. This is a very generous criterion to use to define the transition limits. Previous workers [Fuller et al., 1979] have placed the boundaries at the points where the VGP crosses the $\pm 60^{\circ}$ line of latitude. If we apply this criterion, the transition thickness is $53.5 \mathrm{~cm}(903.8 \mathrm{~cm}$ to $957.3 \mathrm{~cm})$, which yielda a duration estimate of 7,900 years. This could be taken a step further by picking the limits as the $\pm 45^{\circ}$ latitude crosaing of the $\nabla G P$ path [Hoffman, 1977]. Osing this, the transition zone thickness is $30.2 \mathrm{~cm}$, which gives a duration estimate of 4,500 years. These duration estimates would all be too small if the discontinuity at $924 \mathrm{~cm}$ is actually a hiatus, although durations estimates obtained agree with those of 4,000 to 10,000 years made for other reversals [Ninkovich et al., 1966; Harrison and Somayjulu, 1966; Hammond et a 1., 1979; Valet and Laj, 1981; Clement et a 1., 1982].

An estimate of the duration of the intensity change associated with the reversal can be made in a similar manner. The intensity low extendo across a meter of section, from $990 \mathrm{~cm}$ to $890 \mathrm{~cm}$, corresponding to a duration of 14,900 years. If the higha immediately before and after the low are also considered to be a part of the transitional behavior, as has been predicted by some reversal models [Levy, 1983], then the change is recorded from $1005 \mathrm{~cm}$ to $875 \mathrm{~cm}$ with an estimated duration of 19,400 years. In either case the intensity variation associated with the polarity reversal took much longer to occur than the directional change.

\section{Transitional Field Models}

The detailed southern hemisphere record of a reversed to normal transition presented in this paper is of interest in evaluating some current transitional field models. Although there now exists evidence that different reversals may have had very different field geometries [Williams and Fuller, 1982; Bogue and Coe, 1982], the lack of other detailed records of the lower Jaramillo reversal from other sites leaves only records of other R-N reversals to compare this one with. Such a comparison may prove useful, either in providing further constraints on these models or in establishing the validity of comparing different polarity reversal transitions.

Hoffman'a zonal flooding model [Hoffman, 1977] predicts that a transitional $\nabla G P$ path will be 

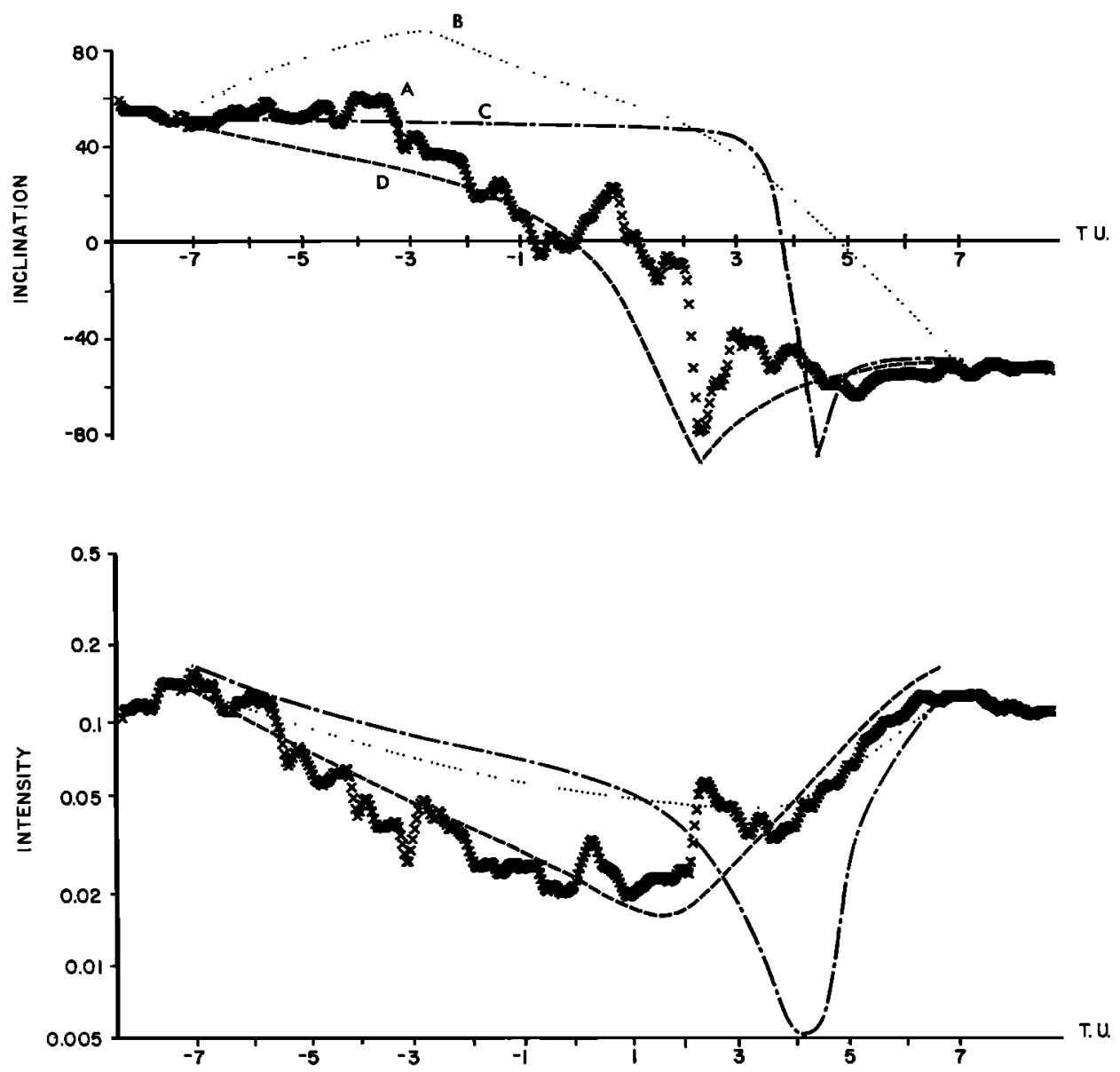

Fig. 4. Five point running mean of the inclination and intensity records from the lower Jaramillo transition (A) plotted together with three synthetic records produced using a Williang-Ful]er [1981] type model. Inclinations plotted in degrees and intensities in $1 \times 10^{-4} \mathrm{~A} \mathrm{~m} / \mathrm{kg}$ versue time units (T. O.). B is the model for the MatuyamaBrunhes field developed by Villiams and Fuller (1981) for a site latitude of $35^{\circ} \mathrm{s}$. Model $C$ was produced by using their model with the ign of the $G_{2}^{0}$ term changed from positive to negative and with only 307 of the available energy going to $G_{3}^{0}$ and $G_{4}^{\circ}$. Model D results from adjusting the energy partitioning in model C.

near-sided or far-sided, depending on a number of factors, including whether the site is in the northern or oouthern hemisphere and whether the transitional field is dominated by a quadrupolar or octupolar field geometry. When Hoffman's [1977] model was developed, the available data (all from the nortbern hemisphere) exhibited a distinct dependence upon the reversal sense: Normal to reversed transitions showed far-sided VGP paths, while reversed to normal reversals had near-sided paths. Recently reported records of a reversed to normal transition with a far-sided VGP path [Williams and Fuller, 1982] and a norma] to reversed transition with a near-sided path [Bogue and Coe, 1982], (both from northern hemishpere sites) make this sense of reversal dependence less apparent.

Nevertheless, the latest reverasl (Matuyama/ Brunhes, R-N) is still characterized by northern hemisphere transition records yielding near-sided VGP patho. When these records are considered together with the record presented here (of the preceeding $R-N$ reversal), the combined data set consists of near-sided VGP patho from the northern hemiephere and a far-sided path from the southern hemisphere. In terms of Hoffman's [1977] model, this suggests that the trangitional fields were characterized by octupolar field geometries. It muat be born in mind, however, that only after other detailed records of the lower Jaramillo reversal and southern hemisphere records of the Matuyama/Brunhes reversal become available will it be possible to determine the differences between the lower Jaramillo and the Matuyamal Brunhes transitions 1 fields.

The model developed by Williams and Fuller [1981] assumes that during a reversal, the dipole field decays exponentially to zero and then builds up again in the opposite direction. As the dipole field decays, the energy it loses is redistributed amongst the lower order, nondipole zonal terms of a spherical harmonic expansion of the field. The energy redistribution was based on the results of Verusob and Cox [1971], which showed that for the last 120 years, $76 \%$ of the energy lost by the dipole term has been gained by the nondipole field with terms of degree $n$ $2,3,4$ receiving 727 of that energy. The WilliamsFuller model can predict the inclination and intensity record that would be observed at any 
oite latitude given particular oet of the various parameters involved.

By fitting synthetic inclination and intensity records to the available records of the Matuyamal Brunhes reversal, Williams and Fuller [1981] were able to model that reversal with $20 \%, 30 \%$ and $50 \%$ of the dipole energy made available to the $G$, $G_{3}^{0}$, and $G_{4}^{O}$ terms respectively. The $\operatorname{cigns}$ of the nondipole terms were kept constant through the reversal with $G_{2}^{0}$ being held positive, $G_{3}^{0}$ negative and $G_{4}^{\circ}$ positive. Their model has been reproduced here, and the record that this model predicts for the ite latitude of $\mathrm{BC} 14-14\left(36^{\circ} \mathrm{S}\right)$ is shown in Figure 4 (curve B). When compared with the data presented here we see that their predicted inclination record passes through steep positive values early in the process, while in the data presented here the inclinations pass through very steep, negative values toward the later part of the reversal (after it passes through the horizontal). In addition, the intensity pattern presented here is more symmetric than their synthet ic intensity record that reaches minimum in the latter part of the reversal.

These differences may be an indication that this modeling technique is inappropriate or that the particular model parameters used by Williams and Fuller [1981] for the Matuyama/Brunhes field are not applicable to the lower Jaramillo transitional field. Although the lack of other detailed records of this reversal makes it impossible to uniquely model its harmonic content, the general character of the record presented here can be approximated by making a few adjustments to their model of the most recent reversal.

The feature of this transition record that controlled our modeling is that the inclinations pass through near vertical negative values after passing through the horizonal. By taking the mode 1 Villiams and Fuller [1981] developed for the Matuyama/Brunhes reversal and changing the Bign of $G_{2}^{\circ}$ from positive to negative and letting it recieve $100 \%$ of the energy lost by the dipole term, aynthetic record for this site can be produced in which the inclinations pass through negative, vertical values in the latter part of the reversal. It vas found that an inclination record exhibiting ateep negative values could be produced as long as no more than $30 \%$ of the energy to be distributed to the nondipole terms var made available to the $G_{3}^{0}$ and $G_{4}^{0}$ terms. The site latitude is located very close to the $G ?$ node. This is why the $G_{2}^{0}$ term must be allowed to gain the majority of the energy in order for it to dominate the higher degree terms. For example, if the energy partitioning is set at $20 \%$ to a negative $G \%, 30 \%$ to a negative $G_{3}^{\circ}$, and $50 \%$ to a positive G $f_{4}$, as in Willians and Fuller's model for the most recent reversal, but with a cutoff of $30 \%$ set for the $G_{3}^{0}$ and $G_{4}^{\circ}$ terms, the record ohown in Figure 4 (curve (C) is produced. If adjustments are made to the energy partitioning, a better fitting synthetic record can be obtained. Reeping the $30 \%$ cutoff, the resulting model partitions the energy with $70 \%$ going to a negative $G_{2}^{0}, 107$ going to a negative $G_{3}^{0}$, and 207 to a positive $G_{4}^{\circ}$. The inclination and intensity records predicted by this version of the model are included in Figure 4 (curve $D$ ). The predicted inclinstion record pases through $-90^{\circ}$ in the latter part of the reversal, in excellent agree- ment with the observed inclinations. In addition, the predicted intensity record appears to fit the observed variation of intengity values quite well.

The results of this modeling support the suggestion [Williams and Puller, 1982; Bogue and Coe, 1982] that different reversals may have been dominated by very different transitional fields. While there are a number of other variations in the Williamo-Fuller model that can approrimate this observed record (no attempt was made here to account for all the details of this record), it may be ignificant that a very good fit is obtained by $s$ imply reversing the 8 ign of the $G_{2}^{0}$ and allowing it to dominate the other terms.

\section{Discussion}

Analyses of the time averaged paleomagnetic field by Merrill and McElhinny [1977] and Merrill et al. [1979] suggest that the lower order, zonal Gausian coefficients change sign when the dipole field reverses. They determined that the ratio of $G_{1}^{\circ}$ to $G_{2}^{0}$ remained positive during both normal and reversed polarity intervals, although during normal intervals the ratio is nearly a factor of $\mathbf{2}$ greater than it was during reversed polarity intervals.

The results of Williams and Fuller's modeling of the Matuyama/Brunhes reversal and the modeling of the lower Jaramillo data presented here suggest that the $G_{2}^{\circ}$ term does not change aign during the polarity transition itself. Pery detailed records would be required to detect reversal of $G_{2}^{0}$ during a non-transitional interval, but it may prove useful to examine seta of sequential reversals in order to learn more about the reversal frequency of $G_{2}^{0}$, e ince zonal harmonic models of transition records appear to be very senoitive to the sign of $G_{2}^{\circ}$.

Bogue and Coe [1982] presented a set of back to back reversals in the time interval 4.5 to 5.6 M.Y. from Rauai $\left(22^{\circ} \mathrm{N}\right)$, both of which exhibit near-sided VGP patho. The inclinations pass through steep downard directions during the latter portion of the R-N transition, but pass through seep downward directions early in the $N-$ R-record. Valet and Laj [1981] obtained a set of successive Miocene reversals from Crete $\left(35^{\circ} \mathrm{N}\right)$, which yielded a $\mathrm{B}-\mathbb{N}$ record with a near-sided VGP path and N-R transition with a far-iided VGP path. Although the VGP path for the reversed to normal reversal is predominantly near-sided, the inclination reoord passes through very steep negative values early in the reversal. The normal to reverse transition in turn exhibits steeply negative inclinations late in the reversal.

Hodeling of these reversal sets reveals that a Villiams and Fuller [1981] type model can produce synthetic inclination records that $f$ it the general character of the observed inclination patterns. If the $G_{2}^{\circ}$ term is allowed to dominate the $G_{3}^{\circ}$ and $G T^{\circ} t^{2} B$, as in our modeling of the lower Jaramillo reversal, reasonable fits for the Kauai records can be obtained by keeping $G_{2}^{\circ}$ positive, $G_{3}^{0}$ negative, and $G_{4}^{0}$ positive for both reversals. In a similar manner the overall character of the crete records can be modeled by letting $G_{2}^{0}$ be negative (maintaining negative $G_{3}^{0}$ - positive Go) through both transitions. The most imple interpretation of these results 
would be that $G_{2}^{0}$ remained the same sign across both reversals in each of these cases. Hovever, the behavior of $G_{?}^{\circ}$ during the intervening nontransitional periods cannot be resolved with these data.

These modeling exercises seem to indicate that the ratio of $G_{1}^{0}$ to $G_{2}^{0}$ may change bign more frequently than was previously thought. This is supported by geomagnetic observatory records that show that this ratio may have changed sign during historical times [Nagata, 1965]. Better knowledge of the different reversal frequencies of the dipole $\left(G_{1}^{0}\right)$ and quadrupole $\left(G_{2}^{0}\right)$ termo mag eventually contribute to an explanation for the asymmetry between normal and reversed polarity fields noted by Merrill and McElhinny [1977] when looking at time averaged fields.

Acknovledgments. The authors would like to thank Lisa Tauxe and John La Brecque for critically reading the manucript and Dann Spariosu for providing assitance with the computing facilities, a well as for their useful discussions. This work was supported by MSF grant OCE83-00356. The Lamont-Doherty Core Laboratory is supported by curatorial grants OCE80-22109 and OCE81-22083. Lamont-Doherty Geological Observatory contribution no. 3571 .

\section{Ref er ences}

Bogue, S. H., and R. S. Coe, Back to back paleomagnetic reversal records from Rauai, Wature, 295, 399-401, 1982.

Clement, B. M., D. V. Rent, and H. D. Opdyke, Brunhes-Matuyama polarity transition in three deep-sea cores, Phil. Trans, ‥ Soc. London, A306, 113-119, 1982 .

Fisher, F. R. S., Dispersion on a sphere, Proc. R. Soc. London Ser. A, 217, 295-305, 1953.

Fuller, M., I. Williams, and R. A. Hoffman, Paleomagnetic records of geomagnetic field reversals and the morphology of the transitional fields, Rey. Geophys. Space Phys., 17, 179-203, 1979.

Hammond, S. R., S. M. Seyb, and F. Theyer, Geomagnetic polarity transitiono in two oriented sediment cores from the northwest Pacific, Earth P1anet. Sci. Lett. 44, 165-175, 1979.

Harrison, C. G. A., and B. L. R. Somayajulu, Behavior of the earth's magnetic field during a reversa1, Nature, 212, 1193-1195, 1966.

Hoffman, R. A., Polarity transition records and the geomagnetic dynamo, Science, 196, 1329, 1977 .

Hoffman, R. A., The testing of geomagnetic reversal models: Recent developments, Phil. Trans. R. Soc, London, A306, 147-154, 1982.

Hoffman, R. A., and M. Fuller, Transitional field configuration and geomagnetic reversals, Neture, 273, 715-178, 1978.
Irving, E., Paleomggnetism and Its Application to Geological and Geophreicel Problems, John Viley, Nev York, 1964.

Levi, S., and S. K. Bannerjee, On the possibility of obtaining relative paleointensities from lake sediments, Earth Planet. Sci, Lett. 29 , 219-226, 1976.

Levy, F. H., Phyaical basis of the geomagnetic reversal phenomenon, Eos Trang. AGU,64, 217, 1983.

Mankinen, E. A., J. H. DonnellyNolan, C. S. Gromme, and B. C. Hearn, Jr., Paleomagnetism of the Clear Lake volcanics and new limits on the age of the Jaramillo polarity event, OSGS Prof. Pap. 1141, 6782, 1980 .

Merril1, R. T., and M. W. McElhinny, Anomalies in the time-averaged paleomagnetic field and their implication for the lower mantle, Rev. Geopbrs. Space Phy8. 15, 309-323, 1977.

Merri11, R. T., M. W. McBlbinny, and D. J. Stevenson, Evidence for long term asymmetries in the earth's magnetic field and possible implications fot dynamo theories, Phys. Earth Planet. Inter. 20, 75-82, 1979.

Nagata, $T$., Main characteriatics of recent geomagnetic secular variation, J. Geomagn. Geoelect.. 17, 263-276, 1965.

Ninkovitch, D., N. D. Opdyke, B. C. Heezen, and J. H. Foster, Paleomagnetic stratigraphy, rates of deposition and tephrachronology in North Pacific deep sea sediment, Earth Planet. Sci. Lett. 1, 476-492, 1966.

Opdyke, N. D., D. V. Rent, and W. Lowrie, Details of magnetic polarity transitions recorded in a high deposition rate deep-sea core, Earth Planet. Sci. Lett., 20, 315- 324, 1973.

Valet, J. P., and C. Laj, Pa leomagnetic record of two successive Miocene geomagnetic reversals in vestern Crete, Earth Planet. Sci, Lett. 54, $53-63,1981$.

Perosub, K. L., and A. Cox, Changes in the tota 1 magnetic energy external to the earts core, J, Geomagn., Geoelectr. 23, 235-242, 1971.

Villiams, I., and M. Fuller, Zonal harmonic models of reversal trangition records, J, Geophys. Re日., 86, 11,657-11,665, 1981 .

Williams, I., and M. Fuller, A Miocene polarity transition (R-N) form the Agno batholith, Luzon, J. Geophys. Res. 87, 9408-9418, 1982.

Zijderveld, J. D. A., A.C. demagnetization of rocks: Analyois of results, in Methods in Paleomagnetism, edited by D. W. Collinson, R. M. Creer, and S. R. Runcorn, Pp. 254-286, Elsevier, New York, 1967.

B. M. Clement and D. V. Rent, Lamont-Doherty Geological Observatory, Palisades, NY 10964

(Received June 8, 1983;

revised October 17, 1983;

accepted October 20,1983.) 